\title{
The Nuffield Home Economics project
}

By Sharon Mansell, West Devon Area Education Department, Plymouth $P L_{1} 2 E W$ and Jenny Salmon, 8 Cherrydale Road, Camberley, Surrey GU 5 I $S R$

Nuffield Home Economics is the first major curriculum development for pupils in the $13-16$ age-range. The materials are designed to cover home economics education in two phases: a basic course for pupils up to the age of 14 years and a 2-year second-phase course to include the $16+$ examination.

The subject is divided into four areas of study:

I. Food science. Food as a resource; the biological, chemical and physical nature of food; the principles of food handling; the methods of preparation and cooking and their effects on food (Nuffield Home Economics, 1983d,e, $1984 a)$.

2. Nutrition. The study of people and food; evidence of the effects of different diets on growth and health; current view-points (Nuffield Home Economics, $1984 b, c, d)$.

3. Fibres and fabrics. Materials and their properties; the importance of textiles in daily life from bandages to car tyres; the principles behind textiles, dress and fashion (Nuffield Home Economics, $1983 a, b, c$ ).

4. People and homes. Homes as shelters and ways of meeting individual and family needs; the scientific principles underlying the effective and economic management of the home and its equipment; child care and development (Nuffield Home Economics, $1984 e, f, g$ ).

In The Basic Course these four areas of study are included in one book for pupils with a teachers' guide in parallel (Nuffield Home Economics, 1982a,b). Each area is divided into seven or eight chapters, to be used as a teaching unit or module on its own. The materials are designed to be flexible in use. They have been planned for mixed-ability groups and give opportunities for extension work. A separate pack of work-sheets and overhead projection (OHP) masters provide data, background information and additional experiments (Nuffield Home Economics, 1982c).

For the second-phase materials, the four areas of study are given in separate pupils' books, each with its separate teachers' guide (Nuffield Home Economics, $\left.198_{3} a, b, d, e, 198{ }_{4} b, c, e, f\right)$. This arrangement allows pupils to specialize in the areas of study of their choice and to develop further the skills and concepts met in The Basic Course. Packs of work-sheets and OHP masters supplement the pupils' text (Nuffield Home Economics, $\mathrm{I}_{98} 3 c, \mathrm{1} 984 a, d, g$ ).

The following criteria have been adopted in selecting the particular topics to be taught. They are: (I) central to home economics teaching; (2) up-to-date, reflecting changing technology and knowledge; (3) scientifically accurate and developing a 
scientific approach; (4) activity based; (5) realistic in an average school using existing facilities; (6) able to give some idea of career possibilities in home economics; (7) relevant to both boys and girls; (8) appropriate to a multi-cultural society. Underlying these criteria, the aims of the course are to: (a) provide pupils with a sound knowledge of the major concepts of home economics and the science underlying them; (b) encourage a scientific approach to practical problems related to home and family; (c) create in pupils an awareness of the impact of rapidly-changing technology on social, economic and family life; (d) help pupils improve their skills in communication, comprehension, verbal fluency and numeracy.

Some of the objectives appear to require a high level of sophistication, but even these are developments of simpler ideas. They can be tackled at quite an early age if the earliest and simplest manifestations of the type of thinking are first identified. The repeated use of these skills, attitudes and ways of thinking and their employment with a slowly-increasing sophistication through the years will make them a real part of the mental make-up of pupils, so that they use them instinctively when tackling problems. Many of these mental attitudes have relevance to the work of the scientist as well as to everyday life. Because only a small percentage of the most able pupils will naturally transfer the skills and objectives gained and apply them to everyday situations, teachers are encouraged to be constantly and continuously offering opportunities for pupils to practice them.

The final point is for the home economics teacher to understand and appreciate the importance of these objectives so that he or she can readily recognize behaviour exhibited by the pupils which shows that the objective is being achieved. A course very largely succeeds or fails because of the way it is taught. How we teach is certainly as important as what we teach. This leads to a whole new field of discussion involving the spirit of teaching nutrition and its associated teaching style.

It was clear from the feedback coming to the Nuffield Project from schools that there is great concern over current issues in nutrition and much eagerness to tackle the problems, but a lack of information on which to base a programme of nutrition that is appropriate to the teacher and pupil.

By definition, a teacher of home economics is unlikely to be a nutritionist or dietitian. Much of the current nutrition information is at the wrong level, perhaps assuming an extent of knowledge that does not exist.

Confusing messages often appear to come through research, the media, the food industry and others with an interest in health education. This confusion has done little to help teachers to recognize the key issues. Neither do many of these so-called teaching aids give any guidance on the best ways of tackling the issues. Should nutrition education in schools be topical, of importance today? Should it be dealing with fundamental concepts in nutrition? Should it also be developing skills for life? If so, what are they?

The secondary curriculum has been defined as an enterprise in the training of 
thoughtful and informed judgement about the varieties of knowledge. What varieties of knowledge are there in nutrition education? How can pupils be 'trained' towards making thoughtful and informed judgements? Given the limited time available for nutrition education within the school curriculum, what is the irreducible minimum content? Why should that be selected? How can it be put across most effectively? How can the learning be assessed? These were some of the issues which exercised the imagination of the project's writers to develop the nutrition materials.

From the outset it was decided that nutritionists should work with teachers so that the final materials would be nutritionally accurate, but suitable for use within the secondary education system. No attempt was made to cover every nutrient in the repertoire, but the team did select those topics, and therefore nutrients, which were felt to be relevant to the health of pupils in the immediate and distant future. After the age of 13 years, many pupils may not receive any further nutrition teaching in school.

\section{The Basic Course (Nuffield Home Economics, 1982a)}

Food in different countries. This first chapter in The Basic Course nutrition section dealt with the well-known fact that many different combinations of foods can promote health. Equally, many cannot. It also tried to get pupils to realize that people are not all the same in terms of their nutrient needs. They vary in size, hair colour and food needs, and a range of sizes, weights and heights is normal. We so often talk about the average (because it is a convenient single measure) that pupils are in danger of thinking this is the only true figure. If they can realize that normality usually covers a range of values, they are more likely to accept the fact that foods vary enormously in composition, and that the figures we so often hear propounded like the 'Gospel according to McCance and Widdowson' are only indicators of the likely composition of a food.

This chapter also puts the role of nutrition into perspective. It may come as a surprise to many to realize that the food we eat is not the cause of all ill-health, nor the cure for every disease. Pupils are encouraged to think about all the other causes of health problems like smoking, bacterial and viral diseases, etc.

What is in food? Pupils then go on to look at what is in various foods. The main ideas in this chapter are that most foods are mainly water and that all foods consist of chemicals. The long-term hope behind this is that perhaps, eventually, people will take a more rational view of food additives and realize that, chemicals though they are, that does not make them of necessity different from the nutrients, flavourings and colourings in foods. By recognizing that foods contain water, pupils are better able to understand that changes in water content can affect the apparent nutrient content of foods.

Energy. Not surprisingly, the authors felt that this chapter was the most important in the nutrition section of the book. The main ideas we tried to get over were that some body fat is normal, even essential and that this fat can be measured quite accurately. Weight is often the only means people have of assessing their 
extent of fatness but it is not always a good measure. Athletic people with a large proportion of muscle will be heavy, but not fat. This chapter begins to cover the concept of energy density of foods and gets pupils to realize that the amount of energy a food provides depends as much on the amount of food eaten as the energy value per unit weight. It recognizes, too, that cooking method can affect the amount of energy eaten. So often we hear people saying that white fish is 'low calorie', and taking no account of the fact that they more than double the amount by frying it.

By burning a peanut, pupils see that energy can be manifested as heat and light, and by running up stairs (and causing chaos in the school) they see that a small amount of energy is actually used in this kind of vigorous activity.

Food choices. This chapter recognizes that people choose foods for a host of reasons. It also acknowledges that many people in the world do not have the luxury of choosing. Among the relevant factors affecting choice are habit, custom, culture, availability, age and the ability to prepare foods.

In looking at the effect of cooking on nutritional value, pupils find out for themselves that although cooking can reduce the concentration of certain vitamins, it also increases palatability so that far more cooked than raw food can be eaten.

Finally, in this chapter, it is re-emphasized that both the concentration of nutrients and the amount of a food that is eaten affect the value of that food in supplying nutrients. Eventually, we may no longer hear people saying that sausages are fattening and apples and meat are not.

Digestion. This topic could, arguably, be left to the biology department, but not every pupil studies biology and there is no guarantee that the full facts will be presented. How many times have we heard that digestion makes molecules small so they can be absorbed? If that is so, how is it that a relatively small sucrose molecule is not absorbed whereas a large vitamin $B_{12}$ molecule is? Digestion introduces the concept of moving nutrients to where they are needed, and enzymes as proteins. Practical work deals with digesting starch.

Finally, the chapter deals with the non-digested nutrients or non-nutrients (dietary fibre) and introduces the idea that fibre is a mixture of many substances each with specific physical and chemical activities.

Food and its effects on health. This chapter draws attention to the fact that when scientists try to find out what causes various supposedly nutrition-related diseases, they frequently turn, at least in the first instance, to epidemiology. The various methods of collecting information about what people eat (dietary surveys, etc.) are summarized and pupils begin to see that just because the intake of a nutrient varies roughly in parallel with the incidence of one or more disorders, it is not necessarily the cause of the disorder. It is probably true that, if more so-called scientists realized this, there would be fewer scares and silly statements made about the cause of heart disease, high blood pressure and obesity.

This section of the book is probably the one which comes closest to more conventional nutrition textbooks because it deals with rickets, and the interrelationship of calcium and vitamin $\mathrm{D}$, as well as the action of sunlight on the skin. It also gives pupils an opportunity to see what acid does to teeth. 
Choosing a nutritious diet. The book continues to try to define a nutritionally-sensible diet, looking specifically at the role of iron. The fact that no single food is essential to every healthy diet is underlined by investigating vegetarian diets. When it comes to assessing the adequacy of the diet, we have no choice but to use recommended daily allowances (RDA), recommended daily intakes (RDI) or similar measures. There is little doubt that these will continue to be applied to individual diets, much to the annoyance of the Department of Health and Social Security, but what else is there? At least this section tries to explain how RDA values are arrived at, so that if they are abused in future, it will be in the full knowledge that they are being abused.

Solving nutrition problems. The last chapter tackles some of the nutrition problems in the world. Not the food shortages in many countries but problems like coeliac disease which can be solved entirely by adjusting the foods eaten. Infant feeding and especially breast-feeding is emphasized so that even if pupils never have another formal nutrition lesson in their lives, they will have heard at least once that breast-feeding offers many benefits to both mother and child.

This brief account of the material in the nutrition section of The Basic Course may give the impression that the whole thing is totally disjointed. To some extent the subjects covered are unrelated to each other but then so are the major issues in nutrition today. From the educational point of view, the scheme is totally logical. The underlying scientific principles are developed throughout and pupils are encouraged to question and investigate rather than to accept the things they are told just because a teacher tells them.

\section{REFERENCES}

Nuffield Home Economics (1982a). The Basic Course. London: Hutchinson Education.

Nuffield Home Economics (1982b). Teachers' Guide to The Basic Course. London: Hutchinson Education.

Nuffield Home Economics (1982c). Worksheet and OHP Masters for The Basic Course. London: Hutchinson Education.

Nuffield Home Economics $(1983 a)$. Fibres and Fabrics. London: Hutchinson Education.

Nuffield Home Economics (1983b). Teachers' Guide to Fibres and Fabrics. London: Hutchinson Education.

Nuffield Home Economics $\left(\mathrm{I}_{9} 83 \mathrm{c}\right)$. Worksheet and Assessment Card Masters for Fibres and Fabrics. London: Hutchinson Education.

Nuffield Home Economics $(1983 d)$. Food Science. London: Hutchinson Education.

Nuffield Home Economics (1983e). Teachers' Guide to Food Science. London: Hutchinson Education.

Nuffield Home Economics (1984a). Worksheet and Assessment Card Masters for Food Science. London: Hutchinson Education.

Nuffield Home Economics ( $1984 b)$. Nutrition. London: Hutchinson Education.

Nuffield Home Economics (1984c). Teachers' Guide to Nutrition. London: Hutchinson Education.

Nuffield Home Economics $\left(\mathrm{I}^{8} 84 d\right)$. Worksheet and Assessment Card Masters for Nutrition. London: Hutchinson Education.

Nuffield Home Economics (1984e). People and Homes. London: Hutchinson Education.

Nuffield Home Economics (1984). Teachers' Guide, People and Homes. London: Hutchinson Education.

Nuffield Home Economics $(19849)$. Worksheet and Assessment Card Masters for People and Homes. London: Hutchinson Education. 